\title{
Prevalence of oral potentially malignant disorders associated with habits in Puducherry - a Cross-sectional study
}

\author{
Swetha Paulose ${ }^{1}$, Vishwanath Rangdhol ${ }^{2}$, \\ Lakshminarayanan Kavya ${ }^{3}$, Govindasamy Ezhumalai ${ }^{4}$
}

${ }^{1}$ Department of Oral Medicine and Radiology, Indira Gandhi Institute of Dental Sciences, Sri Balaji Vidyapeeth University, India

${ }^{2}$ Swarna Dental and Oral Medicine Clinic, Nagawara, Bangalore, Karnataka, Bangalore, India

${ }^{3}$ Parasu Dental Center, Mahindra World City, Chengalpet, Chennai, Tamil Nadu, India

${ }^{4}$ SriBalaji Vidyapeeth University, Puducherry Union Territory, India

Corresponding author: Dr Swetha Paulose Department of Oral Medicine and Radiology, Indira Gandhi Institute of Dental Sciences, Sri Balaji Vidyapeeth University, Puducherry Union Territory-607402, India. Email: swethathomas1981@gmail. com

Phone: 9176070430

Received: June 24, 2019

Accepted: December 02, 2019

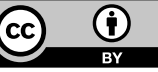

Tobacco and betel quid are the most common cause of oral cancer in India. Very often oral cancers are preceded by a visible oral precursor lesion called as potentially malignant disorder (PMD). Aim: The aim of this study was to assess the prevalence of oral PMDs associated with habits in urban and rural areas of Puducherry Union territory, India. Methods: A cross-sectional descriptive study in urban and rural areas of Puducherry was conducted. The study group comprised of 450 patients with positive history of oral habits. A standard structured questionnaire was designed to record information about demographic details, socioeconomic status, type, duration and frequency of habits followed by clinical oral examination by single trained and calibrated examiner to detect the presence of PMD. Statistical analysis used: EpiData software (version 3.1). Descriptive statistics were presented for all variables. Pearson's Chi-Square test and adjusted odds ratio (ORs) with 95\% confidence interval (Cl) were calculated to estimate the suspected risk factors for PMD by using multivariate logistic regression analysis. P-value of $\leq 0.05$ was considered to be statistically significant. Results: Prevalence of habit associated oral PMD was $64.2 \%$. Females were more prone to develop PMDs (68.3\%) as compared to males $(62.8 \%)$. PMD was more common in the age group of 51-60 years (69.2\%). Smoking with alcohol consumption was the most common oral habit. Habits, socio-economic status and diet were significantly associated with development of oral PMDs in our study population. Multivariate logistic regression analysis showed that chronic betel quid chewing and smoking were significant risk factors for PMD. Increased frequency of vegetable consumption reduced the risk of PMD. Conclusions: Oral PMD were observed in more than half of the subjects with oral habits in Puducherry. Clearly, there is an increased risk of PMD with increased duration of tobacco and betel quid use in this region. Patients and public need to be educated regarding PMD and encouraged to quit habits so as to prevent high risk population from developing cancer.

Keywords: Arecanut. Oral cancer. Potentially malignant disorder 


\section{Introduction}

Among the modern epidemics, cancer is one of the major causes of mortality in developing countries ${ }^{1}$. India has one of the highest rates of oral cancer due to life style related habits such as smoking, betel quid chewing and alcohol. Oral cancers are often preceded by clinically evident precursor lesions called as Potentially Malignant Disorders (PMD). The term PMD introduced by WHO in 2007, conveys that not all lesions and conditions described under this term may transform to cancer, instead there is a family of morphological alterations among which some may have an increased potential for malignant transformation ${ }^{2}$. The overall prevalence of PMD worldwide is reported as $4.47 \%^{3}$. The most important PMDs are Erythroplakia, Oral Leukoplakia (OL), Oral Lichen Planus (OLP) and Oral Submucous Fibrosis (OSMF). Besides oral habits, sun exposure, micronutrient deficiency and socio-economic status are independent risk factors for development of oral PMDs.

Unlike oral cancer, public awareness regarding PMD is very poor in India. Union territory of Puducherry is one among the five districts in India which has recorded a much higher mouth cancer incidence as compared to the global scenario ${ }^{4}$. PMDs offers a good platform to identify the high-risk population. Identifying the risk factors and educating the patients about the ill effects of betel quid, tobacco, alcohol and various other risk factors will help in preventing the development of malignancy in these patients. There is lack of population-based studies in Puducherry, regarding the prevalence of PMDs and its association with various risk factors. Thus, the present study was undertaken to assess the prevalence of oral PMDs in relation to habits in urban and rural population of Puducherry and to understand the clinical profile of these patients.

\section{Materials and methods}

\section{Study design}

A cross-sectional descriptive study was conducted in Puducherry during a 1-year period from 2017-2018 after getting approval from Institutional ethical committee (IGIDSRID2017 NRP06FASPOMR). The district was divided into two zones for the study purpose and a stratified cluster sampling design was employed in which individuals were randomly selected from each zone (villages in rural area and wards in urban areas). With a relative precision of $10 \%$ and design effect of 1.5 , the required sample size was estimated at 274 . The study however included a larger sample in order to improve its precision. A total of 450 eligible participants who met the inclusion criteria were enrolled in the study. The inclusion criteria was that the individual was 15 years or older with history of oral habits and willingness to participate in the study. The study objectives were explained to the participants and written informed consent was taken from every patient in their own language regarding the questionnaire and intraoral examination. Patients below 15 years and without oral habits were excluded from the study. 


\section{Data collection}

Data was collected by a trained dental surgeon using a standardized interviewer-based questionnaire. All the participants were enquired about past or present history of oral habits. A specially designed proforma was used to record the demographic data which included age, gender, occupation, monthly income, marital status (single, married, other), place of residence (rural or urban). The second part of the proforma recorded data on following factors.

\section{Oral habits}

Habits were classified according to number, type, frequency and duration. Type of areca quid (areca nut, mawa, pan masala, gutkha) along with or without tobacco and lime, location of quid placement etc were recorded. Tobacco was used to refer to the use of dried tobacco leaves. Smoking included cigarette/beedi/pipe smoking. Betel quid was used to refer to the use of betel nut and lime.

\section{Socioeconomic status}

Socioeconomic status was assessed using B.G. Prasad's socio-economic status scale (2015). The SES index was categorized into 5 index quartiles based on their per capita monthly income. The minimum value of the SES index was 0-869 and maximum value was 5798 and above.

\section{Dietary Intake}

The dietary risk factors were evaluated on a six-point Likert scale based on the frequency of vegetable and fruit intake per day. The subjects were further classified into specific groups based on the frequency of vegetable and fruit intake.

The interview was followed by a thorough clinical examination of the oral cavity which was performed by trained dental professional to identify the PMDs based on well-established clinical features of the lesions. Subjects were asked to rinse their mouth prior to the examination. All the study participants were explained about the adverse effects of oral habits and counselling was given regarding habit cessation. Subjects diagnosed with PMD were referred to our Institution for further investigations and management.

\section{Statistical analysis}

The recorded data from the 450 cases and controls was entered and analysed using EpiData software (version 3.1) Descriptive statistics were presented for all variables. Pearson's Chi-Square test and adjusted odds ratio (ORs) with 95\% confidence interval $(\mathrm{Cl})$ were calculated to estimate the suspected risk factors for PMD by using multivariate logistic regression analysis. P-value of $\leq 0.05$ was considered to be statistically significant.

\section{Results}

Table 1 presents the demographic characteristics of study participants. Among 450 participants with oral habits, there were 349 men (77.5\%) and 101 women (22.4\%). 
Table 1. Distribution of subjects according to Age, Gender, Area of residence and PMD.

\begin{tabular}{|c|c|c|c|c|c|}
\hline \multirow{2}{*}{ Variable } & \multicolumn{2}{|c|}{ PMD } & \multirow{2}{*}{ Chi-square value } & \multirow{2}{*}{ df } & \multirow{2}{*}{ P-value } \\
\hline & Yes (\%) & No (\%) & & & \\
\hline Total & $288(64)$ & $162(36)$ & & & \\
\hline \multicolumn{6}{|l|}{ Age(years) } \\
\hline$\leq 30$ & $19(51.4)$ & $18(48.6)$ & \multirow{5}{*}{5.57} & \multirow{5}{*}{4} & \multirow{5}{*}{0.23} \\
\hline $31-40$ & $30(60.0)$ & $20(40.0)$ & & & \\
\hline $41-50$ & $78(60.9)$ & $50(39.1)$ & & & \\
\hline $51-60$ & $92(69.2)$ & $41(30.8)$ & & & \\
\hline$\geq 60$ & $69(67.6)$ & $33(32.4)$ & & & \\
\hline \multicolumn{6}{|l|}{ Gender } \\
\hline Male & $219(62.8)$ & $130(37.2)$ & \multirow{2}{*}{1.05} & \multirow{2}{*}{1} & \multirow{2}{*}{0.30} \\
\hline Female & $69(68.3)$ & $32(31.7)$ & & & \\
\hline \multicolumn{6}{|l|}{ Area } \\
\hline Urban & $119(64.7)$ & $65(35.3)$ & \multirow{2}{*}{0.06} & \multirow{2}{*}{1} & \multirow{2}{*}{0.80} \\
\hline Rural & $169(63.5)$ & $97(36.5)$ & & & \\
\hline
\end{tabular}

Mean age group of the study population was 51 years. Overall prevalence of PMD was $64.2 \%$. PMD was more common among females (68.3\%) than males (62.8\%). Leukoplakia (54.2\%) was the most common PMD noticed followed by OSMF (8.4\%) and lichen planus (0.6\%). Least common PMD identified was erythroplakia. Some of them had more than one lesion. There was slightly more cases of PMD among the urban population compared to rural areas (64.7\% vs 63.5\%). However, there was no significant association between age, gender, area of residence and presence of PMDs ( $P$ values $=0.23,0.30$ and 0.80 respectively).

Table 2 presents the association between oral habits and PMD. Highest number of PMDs were observed in group 7 (smoking with alcohol habit) $(n=88)$ followed by betel

Table 2. Distribution of subjects according to Habits and PMD

\begin{tabular}{|c|c|c|c|c|c|}
\hline \multirow{2}{*}{ SI No } & \multirow{2}{*}{ Habits } & \multicolumn{2}{|c|}{ PMD } & \multirow{2}{*}{ Chi-square value } & \multirow{2}{*}{ P-value } \\
\hline & & Yes (\%) & $\mathrm{No}(\%)$ & & \\
\hline 1. & Betel nut + Lime & $20(74.1 \%)$ & $7(25.9 \%)$ & \multirow{12}{*}{24.98} & \multirow{12}{*}{0.009} \\
\hline 2. & Tobacco leaf & $9(100 \%)$ & $0(0 \%)$ & & \\
\hline 3. & Smoking & $35(53.8 \%)$ & $30(46.2 \%)$ & & \\
\hline 4. & Alcohol & $2(28.6 \%)$ & $5(71.4 \%)$ & & \\
\hline 5. & Betel quid + tobacco leaf & $67(62.0 \%)$ & $41(38.0 \%)$ & & \\
\hline 6. & Betel quid+ Alcohol & $3(50.0 \%)$ & $3(50.0 \%)$ & & \\
\hline 7. & Smoking+ Alcohol & $88(64.2 \%)$ & $49(35.8 \%)$ & & \\
\hline 8. & Tobacco + Alcohol & $2(100 \%)$ & $0(0 \%)$ & & \\
\hline 9. & Betel quid + Tobacco + Alcohol & $31(60.8 \%)$ & $20(39.2 \%)$ & & \\
\hline 10. & Betel quid+ Tobacco+ Smoking & $14(82.4 \%)$ & $3(17.6 \%)$ & & \\
\hline 11. & Betel quid + Smoking + Alcohol & $2(100.0 \%)$ & $0(0 \%)$ & & \\
\hline 12. & Betel quid +Tobacco+Smoking+Alcohol & $15(78.9 \%)$ & $4(21.1 \%)$ & & \\
\hline
\end{tabular}


quid chewing with tobacco $(n=67)$. The types of betel quid chewing varied from traditional Paan consisting of betel leaf wrapped around a mixture of areca or betel nut (nut of Areca catechu), slaked lime, catechu (extract of Acacia)with or without dried tobacco leaf to Gutkha, Hans, Pan Parag and other commercially available tobacco products. Statistically significant difference was observed between various forms of oral habits and development of PMDs. ( $P$ value $=0.009)$. Adjusted residual value for habit-2 (smokeless tobacco chewing) was 2.3 which implies that dried tobacco leaf is a major contributory factor for development of PMD.

Table 3, Table 4 and Table 5 presents the correlation of duration of habits and PMD. There was a significant association between chronic betel quid chewing and smoking with PMD. ( $P$ value $=0.01$ and 0.00 respectively). However there was no significant association between PMD and duration of alcohol consumption (P value= 0.20).

Table 6 presents the correlation of PMD with SES. Majority of the patients belonged to the 0-869 SES index quartile. Chi-square analysis showed statistically significant difference in SES index and PMDs. (P value $=0.003) 78.6 \%$ of the study population diag-

Table 3. Distribution of subjects according to duration of betel quid chewing and PMD.

\begin{tabular}{|c|c|c|c|c|c|}
\hline \multirow{2}{*}{ SI No } & \multirow{2}{*}{ Duration of betel quid habit (years) } & \multicolumn{2}{|c|}{ PMD } & \multirow{2}{*}{ Chi-square value } & \multirow{2}{*}{ P-value } \\
\hline & & Yes(\%) & $\mathrm{No}(\%)$ & & \\
\hline 1. & $\leq 30$ & $136(59.6 \%)$ & $92(40.4 \%)$ & \multirow{5}{*}{13.36} & \multirow{5}{*}{0.01} \\
\hline 2. & $31-40$ & $41(59.4 \%)$ & $28(40.6 \%)$ & & \\
\hline 3. & $41-50$ & $32(74.4 \%)$ & $11(25.6 \%)$ & & \\
\hline 4. & $51-60$ & $27(90.0 \%)$ & $3(10.0 \%)$ & & \\
\hline 5. & $\geq 60$ & $52(65.0 \%)$ & $28(35.0 \%)$ & & \\
\hline
\end{tabular}

Table 4. Distribution of subjects according to duration of smoking and PMD

\begin{tabular}{|c|c|c|c|c|c|}
\hline \multirow{2}{*}{ SI No } & \multirow{2}{*}{ Duration of smoking habit (years) } & \multicolumn{2}{|c|}{ PMD } & \multirow{2}{*}{ Chi-square value } & \multirow{2}{*}{ P-value } \\
\hline & & Yes (\%) & No $(\%)$ & & \\
\hline 1. & $\leq 30$ & $136(63.3 \%)$ & $79(36.7 \%)$ & \multirow{5}{*}{21.8} & \multirow{5}{*}{0.00} \\
\hline 2. & $31-40$ & $22(40.7 \%)$ & $32(59.3 \%)$ & & \\
\hline 3. & $41-50$ & $48(68.6 \%)$ & $22(31.4 \%)$ & & \\
\hline 4. & $51-60$ & $21(91.3 \%)$ & $2(8.7 \%)$ & & \\
\hline 5. & $\geq 60$ & $61(69.3 \%)$ & $27(30.7 \%)$ & & \\
\hline
\end{tabular}

Table 5. Distribution of subjects according to duration of alcohol drinking and PMD

\begin{tabular}{|c|c|c|c|c|c|}
\hline \multirow{2}{*}{ SI No } & \multirow{2}{*}{ Duration of alcohol habit (years) } & \multicolumn{2}{|c|}{ PMD } & \multirow{2}{*}{ Chi-square value } & \multirow{2}{*}{ P-value } \\
\hline & & Yes(\%) & No $(\%)$ & & \\
\hline 1. & $\leq 30$ & $146(62.9 \%)$ & $86(37.1 \%)$ & \multirow{5}{*}{5.97} & \multirow{5}{*}{0.20} \\
\hline 2. & $31-40$ & $37(66.1 \%)$ & $19(33.9 \%)$ & & \\
\hline 3. & $41-50$ & $35(55.6 \%$ & $28(44.4 \%)$ & & \\
\hline 4. & $51-60$ & $22(81.5 \%)$ & $5(18.5 \%)$ & & \\
\hline 5. & $\geq 60$ & $48(66.7 \%)$ & $24(33.3 \%)$ & & \\
\hline
\end{tabular}


Table 6. Distribution of subjects according to socioeconomic status and PMD

\begin{tabular}{|c|c|c|c|c|}
\hline \multirow{2}{*}{ Per capita monthly income } & \multicolumn{2}{|c|}{ PMD } & \multirow{2}{*}{ Chi-square value } & \multirow{2}{*}{ P-value } \\
\hline & Yes n (\%) & No $n(\%)$ & & \\
\hline $0-869$ & $91(53.2)$ & $80(46.8)$ & \multirow{5}{*}{16.30} & \multirow{5}{*}{0.003} \\
\hline 870-1738 & $80(66.1)$ & $41(33.9)$ & & \\
\hline 1739-2898 & $58(72.5)$ & $22(27.5)$ & & \\
\hline 2899-5797 & $33(78.6)$ & $9(21.4)$ & & \\
\hline 5798-Infinity & $26(72.2)$ & $10(27.8)$ & & \\
\hline
\end{tabular}

nosed with PMDs belonged to families in the higher SES group with monthly income 2899-5797 and least number was noticed in the lower SES group (53.2\%).

Table 7 and Table 8 presents the correlation of Nutritional Intake and PMD. PMD was more common in patients who had less vegetable intake compared to those who took vegetables several times a day and the association was statistically significant. ( $P$ value $=0.001$ ). There was higher prevalence of PMDs among individuals with reduced fruit consumption. There was statistically significant association between frequency of fruit consumption and PMD (P value= 0.002)

Table 9 presents Multivariate analysis of different variables in cases with PMD. The data were analysed by multiple regression using age, gender, place of residence (urban/rural), habit duration, SES, vegetable and fruit intake as regressors. Duration of betel quid chewing and smoking, frequency of vegetable intake interacted, and

Table 7. Distribution of subjects according to frequency of vegetable intake and PMD

\begin{tabular}{|c|c|c|c|c|c|}
\hline \multirow{2}{*}{ SI No } & \multirow{2}{*}{ Frequency of vegetable intake } & \multicolumn{2}{|c|}{ PMD } & \multirow{2}{*}{ Chi-square value } & \multirow{2}{*}{ P-value } \\
\hline & & Yes (\%) & No (\%) & & \\
\hline 1. & Several times a day & $30(65.2 \%)$ & $16(34.8 \%)$ & \multirow{5}{*}{17.6} & \multirow{5}{*}{0.001} \\
\hline 2. & Everyday & $180(59.0)$ & $125(41.0 \%)$ & & \\
\hline 3. & Several times week & $65(83.3 \%)$ & $13(16.7 \%)$ & & \\
\hline 4. & Once a week & $3(42.9 \%)$ & $4(57.1 \%)$ & & \\
\hline 5. & Several times a month & $10(71.4 \%)$ & $4(28.6 \%)$ & & \\
\hline 6. & Seldom/Never & 0 & 0 & & \\
\hline
\end{tabular}

Table 8. Distribution of subjects according to frequency of fruits intake and PMD

\begin{tabular}{|c|c|c|c|c|c|}
\hline \multirow{2}{*}{ SI No } & \multirow{2}{*}{ Frequency of fruits intake } & \multicolumn{2}{|c|}{ PMD } & \multirow{2}{*}{ Chi-square value } & \multirow{2}{*}{ P-value } \\
\hline & & Yes(\%) & No (\%) & & \\
\hline 1. & Several times a day & $0(0 \%)$ & $2(100 \%)$ & \multirow{5}{*}{18.46} & \multirow{5}{*}{0.002} \\
\hline 2. & Everyday & $11(37.9 \%)$ & $18(62.1 \%)$ & & \\
\hline 3. & Several times week & $49(64.5 \%)$ & $27(35.5 \%)$ & & \\
\hline 4. & Once a week & $20(50.0 \%)$ & $20(50.0 \%)$ & & \\
\hline 5. & Several times a month & $94(69.6 \%)$ & $41(30.4 \%)$ & & \\
\hline 6. & Seldom/Never & $114(67.9 \%)$ & $54(32.1 \%)$ & & \\
\hline
\end{tabular}


Table 9. Multivariate analysis of different variables in cases with PMD

\begin{tabular}{|c|c|c|c|c|c|c|c|c|}
\hline \multirow{2}{*}{ Variables } & \multirow{2}{*}{ b } & \multirow{2}{*}{ s.e. } & \multirow{2}{*}{$\begin{array}{c}\text { Wald } \\
\text { chisquare }\end{array}$} & \multirow{2}{*}{ df } & \multirow{2}{*}{$p$ value } & \multirow{2}{*}{ or } & \multicolumn{2}{|c|}{$95.0 \%$ ci for or } \\
\hline & & & & & & & Lower & Upper \\
\hline \multicolumn{9}{|l|}{ Age group(years) } \\
\hline$\leq 30$ & & & 2.240 & 4 & .692 & & & \\
\hline $31-40$ & .371 & .508 & .532 & 1 & .466 & 1.449 & .535 & 3.926 \\
\hline $41-50$ & .068 & .457 & .022 & 1 & .882 & 1.070 & .437 & 2.620 \\
\hline $51-60$ & .465 & .472 & .972 & 1 & .324 & 1.593 & .631 & 4.018 \\
\hline$\geq 60$ & .312 & .497 & .395 & 1 & .530 & 1.367 & .516 & 3.620 \\
\hline Gender & .490 & .362 & 1.836 & 1 & .175 & 1.632 & .804 & 3.315 \\
\hline Area of residence & -.279 & .247 & 1.271 & 1 & .260 & .757 & .466 & 1.228 \\
\hline \multicolumn{9}{|l|}{ Duration of habits (years) } \\
\hline \multicolumn{9}{|l|}{ Alcohol } \\
\hline$\leq 30$ & & & 4.807 & 4 & .308 & & & \\
\hline $31-40$ & .400 & .378 & 1.124 & 1 & .289 & 1.492 & .712 & 3.128 \\
\hline $41-50$ & -.214 & .350 & .374 & 1 & .541 & .807 & .407 & 1.602 \\
\hline $51-60$ & .993 & .601 & 2.735 & 1 & .098 & 2.700 & .832 & 8.761 \\
\hline$\geq 60$ & .171 & .364 & .221 & 1 & .638 & 1.187 & .582 & 2.421 \\
\hline \multicolumn{9}{|l|}{ Betel quid } \\
\hline$\leq 30$ & & & 16.034 & 4 & .003 & & & \\
\hline $31-40$ & .498 & .376 & 1.753 & 1 & .186 & 1.646 & .787 & 3.442 \\
\hline $41-50$ & 1.272 & .476 & 7.146 & 1 & .008 & 3.568 & 1.404 & 9.067 \\
\hline $51-60$ & 2.587 & .728 & 12.645 & 1 & .000 & 13.292 & 3.194 & 55.319 \\
\hline$\geq 60$ & .685 & .426 & 2.593 & 1 & .107 & 1.984 & .862 & 4.570 \\
\hline \multicolumn{9}{|l|}{ Smoking } \\
\hline$\leq 30$ & & & 23.223 & 4 & .000 & & & \\
\hline $31-40$ & -.151 & .434 & .122 & 1 & .727 & .860 & .367 & 2.010 \\
\hline $41-50$ & 1.221 & .421 & 8.423 & 1 & .004 & 3.391 & 1.486 & 7.734 \\
\hline $51-60$ & 2.454 & .833 & 8.676 & 1 & .003 & 11.633 & 2.273 & 59.544 \\
\hline$\geq 60$ years & 1.085 & .420 & 6.683 & 1 & .010 & 2.960 & 1.300 & 6.737 \\
\hline \multicolumn{9}{|c|}{ Frequency of vegetables and fruits consumption } \\
\hline \multicolumn{9}{|l|}{ Fruits } \\
\hline Several times a day & & & 13.577 & 5 & .019 & & & \\
\hline Once a day & 20.753 & $2.799 \mathrm{e} 4$ & .000 & 1 & .999 & $1.030 \mathrm{e} 9$ & .000 & . \\
\hline Several times a week & 22.343 & $2.799 \mathrm{e} 4$ & .000 & 1 & .999 & $5.054 \mathrm{e} 9$ & .000 & . \\
\hline Once a week & 21.566 & $2.799 \mathrm{e} 4$ & .000 & 1 & .999 & $2.322 \mathrm{e} 9$ & .000 & . \\
\hline Several times a month & 22.438 & $2.799 \mathrm{e} 4$ & .000 & 1 & .999 & $5.554 \mathrm{e} 9$ & .000 & . \\
\hline Seldom/never & 22.139 & $2.799 \mathrm{e} 4$ & .000 & 1 & .999 & $4.118 \mathrm{e} 9$ & .000 & . \\
\hline \multicolumn{9}{|l|}{ Veg } \\
\hline Several times a day & & & 13.722 & 4 & .008 & & & \\
\hline Once a day & -.868 & .425 & 4.160 & 1 & .041 & .420 & .182 & .967 \\
\hline Several times a week & .192 & .536 & .128 & 1 & .721 & 1.211 & .424 & 3.463 \\
\hline once a week & -1.650 & .920 & 3.214 & 1 & .073 & .192 & .032 & 1.166 \\
\hline Several times a month & -.599 & .783 & .586 & 1 & .444 & .549 & .118 & 2.547 \\
\hline Constant & -22.097 & $2.799 \mathrm{e} 4$ & .000 & 1 & .999 & .000 & & \\
\hline
\end{tabular}

$b=$ parameter estimate $\beta$, se = standard error, $d f=$ degree of freedom, or= odd's ratio, $c i=$ confidence interval 
showed strong association with development of PMD. Patients with history of smoking for 50-60 years had 11 times more risk of developing PMDs. Similarly, those who had chronic betel quid chewing habit for 50-60 years were 13 times more prone to develop PMD. Vegetable consumption everyday reduced the risk of PMD by $58 \%$.

\section{Discussion}

Among 450 participants in our study, PMD was identified among 288 individuals (64.2\%) which is consistent with the reports by Kadashetti et al. ${ }^{1}$ in Maharashtra (65\%). Our results were less compared to the corresponding values of $77.1 \%$ reported by Gupta et al. ${ }^{5}$ in Lucknow but distinctly higher than several other studies in India such as Saraswathi et al. ${ }^{6}$ in Chennai, Tamil Nadu(4.1\%), Vinay et al. ${ }^{7}$ Telangana (4.2\%), Thada and $\mathrm{Pai}^{8}$ Manipal, (27.67\%) and Narasannavar and Wantamuttet ${ }^{9}$ Belgaum (Karnataka) (51.21\%). The wide variation among the prevalence rates of PMD may be attributed to the changing trends in oral habits in various parts of the country and other associated risk factors like cultural, socioeconomic and environmental factors.

We observed that highest number of PMD cases were in 50-60 yrs of age group (69.2\%). This was comparable to the results from Kadashhetti et al. ${ }^{1}$, Saraswathi et al. ${ }^{6}$ and Jagtap et al. ${ }^{10}$. Several studies have reported equal prevalence of PMD among the middle aged and elderly subjects ${ }^{8}$ whereas few others have reported highest prevalence in 21-30 years of age group ${ }^{11}$ which was not in accordance with our study. This difference could be attributed to the study design and variation in habit pattern among different age groups with respect to different states.

Males have been reported to be more frequently affected by PMD due to higher prevalence of oral habits among men 1,11,12. Female predilection has been reported in few places such as Manipal, southern Karnataka (59.30\%) ${ }^{8}$ and this finding was in concordance with our results. However, age, gender and area of residence were found to be neither a risk nor a protective factor for PMDs in our population.

Smoking with alcohol was the most common oral habit (30.4\%) prevalent in this area. Among single habit, smoking was the most common habit (14.4\%). Similar to our findings, smoke form of tobacco was reported as the most common form of tobacco used in Puducherry (64\%) by Aroquiadas et al. ${ }^{13}$. High prevalence of alcohol consumption has been noted among adult men (59.6\%) in coastal areas of Puducherry due to easy availability of alcohol at a subsidized rate ${ }^{14}$.

Habits were significantly associated with PMDs ( $P$ value $=0.009)$. Our study results were in agreement with the studies conducted at different parts of world 1,8,15,16,17. Maximum number of PMD cases were seen among smokers with alcohol consumption habit (64.2\%) which was consistent with the study by Marija et al. ${ }^{18}$ and Baric et al. ${ }^{19}$. Localized elevation in the temperature of the oral cavity following smoking, makes the epithelium more susceptible to genotoxic effect of tobacco products. Ethanol as a solvent may damage the oral cells and increase the mucosal penetration of these toxic carcinogens. Based on the adjusted residual values, it was found that tobacco leaf is a significant predictor for development of PMD. Tobacco use in any form can trigger changes including inflammation, atrophy and hypertrophy of the mucosa, leading to development of PMD and oral cancer ${ }^{20}$. Betel quid chewing with tobacco is said 
to have an increased carcinogenic potential because it remains in contact with the oral mucosa for longer period of time compared to smoking/alcohol17.

Chronicity and increase in number of habits have been associated with increased risk of oral cancer and $\mathrm{PMD}^{8}$. In the current study, we noticed that duration of smoking and betel quid chewing were significant risk factor for PMD but not alcohol duration. It is possible that alcohol contributes to the development of PMDs in the presence of other habits such as betel quid chewing /smoking.

Alcohol has been proved to be a risk factor for oral cancer ${ }^{21}$, but not for PMD ${ }^{5}$. Some studies did not show any association between drinking and the risk of oral PMD. While other studies that showed associations had not adjusted for potential confounders such as tobacco chewing and smoking ${ }^{22}$.

The most common PMD noticed among the study population was Leukoplakia (54.2\%) followed by OSMF and Lichen planus. Homogeneous leukoplakia was more frequently seen than non-homogeneous type. Leukoplakia was identified as the most common PMD by Hosagadde et al. ${ }^{11}$, in Mumbai (45.71\%) and Aroquiadasse et al. ${ }^{15}$, in Pondicherry (38.4\%). There are contradictory results from other studies where OSMF 2,12,17,23 and Lichen planus were found to be most prevalent PMD24. This alteration could be due to the differences in chronicity, composition, method of smoking/ chewing and combinations of habits which is prevalent in respective areas. In our study, buccal mucosa was the most common site affected which was comparable to the observations made by Thada et al. ${ }^{8}$, Zain et al. ${ }^{20}$ and Mortazav et al. ${ }^{25}$.

Socioeconomic status showed strong association with PMD in our study population $(P$ value $=0.003)$. Changes in income are more likely to affect the tobacco, alcohol / betel quid usage ${ }^{26}$. Most of our study subjects belonged to the lower socio-economic group with family income less than Rs 869 per month. We believed that economically poor people are at an increased risk of developing oral cancer and PMD due to insufficient nutrition coupled with lack of oral health awareness ${ }^{27}$. However, the figures were very surprising as our data showed that most of the PMD lesions were observed in the middle and higher socioeconomic strata perhaps because of changing life style risk factors. This was matching with the observations made by Gupta et al. ${ }^{5}$ in Lucknow. The authors had reported that lower income group was at a lesser risk of developing OSMF and leukoplakia. In our study, we had taken into consideration only per capita monthly income as a variable to assess SES. Literacy rate/education, occupation etc may also affect the socioeconomic status. More longitudinal studies are recommended in this direction to determine the causal relationship to PMD.

Frequency of fruits and vegetable intake were significantly associated with PMD in our study population ( $P$ value $=0.002$ and 0.001 respectively). Majority of the subjects were frequent consumers of vegetables but not fruits. On multiple regression analysis we found that increased vegetable intake significantly reduces the risk of PMD. Kumar et al. ${ }^{12}$ and Pahwa et al. ${ }^{28}$ have reported that among patients with PMD, majority were infrequent consumers of fruits and vegetables. While the protective role of antioxidant rich diet against oral cancer and PMDs is well established, data regarding the same in Indian population is meagre. Dietary habits of Indians are in fact influenced by their socioeconomic status, culture and religious beliefs. Antioxidant rich diet in sufficient 
quantity is essential to protect against free radical induced oxidative damage which is precipitated in the presence of tobacco, betel nut and alcohol. Our study results emphasize the importance of educating the patients regarding the importance of diet in maintaining oral health.

Results of Logistic Regression analysis showed that chronic betel quid chewing, smoking and reduced frequency of vegetable intake are the major risk factors for development of oral PMD.

Our study being a community-based survey provides the baseline data regarding the prevalence of PMD in this region. To our knowledge, this is the first study to investigate the prevalence of PMD in association with the habit trends and potential risk factors in Puducherry population. However, there were some limitations. Causal relationships between the risk factors and PMDs were not completely clear due to the use of a cross-sectional design. Diet pattern was not analysed with respect to quality of food. Finally, there may have been some unrecognized confounding factors.

The results of our study highlight the fact that individuals with oral habits in Puducherry are at high risk of developing PMD. Chronic smoking and betel quid chewing are the major risk factors for development of PMD. Frequent intake of vegetables may serve as a protective factor in these individuals. Socioeconomic status has an impact on individual oral health and development of PMD which could be related to lifestyle risk factors. Oral health planners should address the socioeconomic status of the population while planning and evaluation of oral health care programs.

As health professionals it is our duty to educate the public regarding the consequences of tobacco, alcohol and betel quid chewing habits. We suggest that every dental teaching institution should have a trained personal to operate a habit counselling clinic to promote and assist those who want to quit the habit. The knowledge regarding $\mathrm{PMD}$, its associated risk factors and susceptibility to develop cancer must be imparted by awareness programs. Early intervention in initial risk populations will help us to prevent irrevocable changes in oral mucosa.

\section{Conflicts of Interest}

Nil.

\section{Source of Funding}

Nil.

\section{References}

1. Kadashetti V, Chaudhary M, Patil S, Gawande M, Shivakumar KM, Patil S, et al. Analysis of various risk factors affecting potentially malignant disorders and oral cancer patients of Central India. J Cancer Res Ther. 2015 Apr-Jun;11(2):280-6. doi: 10.4103/0973-1482.151417.

2. Warnakulasuriya S. Clinical features and presentation of oral potentially malignant disorders. Oral Surg Oral Med Oral Pathol Oral Radiol. 2018 Jun;125(6):582-590. doi: 10.1016/j.0000.2018.03.011 
3. Mello FW, Miguel AFP, Dutra KL, Porporatti AL, Warnakulasuriya S, Guerra ENS, et al. Prevalence of oral potentially malignant disorders: a systematic review and meta-analysis. J Oral Pathol Med. 2018 Aug;47(7):633-640. doi: 10.1111/jop.12726.

4. Bhardwaj N, Daniel MJ, Srinivasan SV, Jimsha VK. Demographics, habits, and clinical presentation of oral cancer in Puducherry's population: An institutional experience. J Indian Acad Dent Spec Res. 2015;2(2):64-9. doi: 10.4103/2229-3019.177926.

5. Gupta S, Singh R, Gupta OP, Tripathi A. Prevalence of oral cancer and pre-cancerous lesions and the association with numerous risk factors in North India: A hospital based study. Natl J Maxillofac Surg. 2014 Jul-Dec;5(2):142-8. doi: 10.4103/0975-5950.154816.

6. Saraswathi TR1, Ranganathan K, Shanmugam S, Sowmya R, Narasimhan PD, Gunaseelan R. Prevalence of oral lesions in relation to habits: Cross-sectional study in South India. Indian J Dent Res. 2006 Jul-Sep;17(3):121-5.

7. Vinay BH, Baghirath PV, Kumar JV, Arvind. Prevalence of precancerous lesions and conditions in Telangana region, Andhra Pradesh, India. J Indian Assoc Public Health Dent. 2014;12(1):23-7. doi : 10.4103/2319-5932.138904.

8. Thada SR, Pai KM. Prevalence of habit associated oral mucosal lesions among the outpatients - A prospective cross sectional study. Int J Res Health Sci. 2014 Jan31;2(1):263-73.

9. Narasannavar A,Wantamuttet A. Prevalence of oral precancerous lesions and conditions among tobacco consumers in rural population around Belgaum. A community based cross sectional study. IOSR J Dent Med Sci. 2014 Apr;13(4):31-4. doi: 10.9790/0853-13433134.

10. Jagtap SV, Warhate P, Saini N, Jagtap SS, Chougule PG. Oral premalignant lesions: a clinicopathological study. Int Surg J. 2017;4(10):3477-81. doi: 10.18203/2349-2902.isj20174520.

11. Hosagadde S, Dabholkar J, Virmani N. A clinicopathological study of oral potentially malignant disorders. J Head Neck Physicians Surg. 2016;4(1):2934. doi: 10.4103/2347-8128.182853.

12. Kumar S, Debnath N, Ismail MB, Kumar A, Kumar A, Badiyani BK, et al. Prevalence and Risk Factors for Oral Potentially Malignant Disorders in Indian Population. Adv Prev Med. 2015;2015:208519. doi: 10.1155/2015/208519.

13. Aroquiadasse M, Daniel MJ, Srinivasan SV, Jimsha VK. Correlation of degree of dysplasia in potentially malignant disorders with tobacco use: A cross-sectional study. Clin Cancer Investig J. 2016;5(5):398-402. doi: 10.4103/2278-0513.197870.

14. Easwaran M, BazroyJ, Jayaseelan V, Singh Z. Prevalence and determinants of alcohol consumption among adult men in a coastal area of South India. Int J Med Sci Public Health 2015;4(3):360-4. doi: 10.5455/ijmsph.2015.1010201479.

15. Ariyawardana A, Sitheeque MA, Ranasinghe AW, Perera I, Tilakaratne WM, Amaratunga EA, et al. Prevalence of oral cancer, precancer and associated risk factors among tea estate workers in the central Sri Lanka. J Oral Pathol Med. 2007 Nov;36(10):581-7.

16. Hashibe M, Mathew B, Kuruvilla B, Thomas G, Sankaranarayanan R, Parkin DM, et al. Chewing tobacco, alcohol, and the risk of erythroplakia. Cancer Epidemiol Biomarkers Prev. 2000 Jul;9(7):639-45.

17. Sawyer DR, Wood NK. Oral cancer: Etiology, recognition and management. Dent Clin North Am. 1992 Oct;36(4):919-44.

18. Marija, Bratic B, Vuckovic N. Cigarette Smoking as a risk factor associated with oral leukoplakia. Arch Oncol. 2002;10(2):67-70. doi: 10.2298/A000202067B.

19. Baric JM, Alman JE, Feldman RS, Chauncey HH. Influence of cigarette, pipe and cigar smoking, removable partial dentures and age on oral leukoplakia. Oral Surg Oral Med Oral Pathol. 1982 Oct;54(4):424-9. 
20. Zain RB, Ikeda N, Gupta PC, Warnakulasuriya S, van Wyk CW, Shrestha P, et al. Oral mucosal lesions associated with betel quid, areca nut and tobacco chewing habits: consensus from a workshop held in Kuala Lumpur, Malaysia, November 25-27, 1996. J Oral Pathol Med. 1999 Jan;28(1):1-4.

21. Sankaranarayanan R, Duffy SW, Padmakumary G, Day NE, Krishan Nair M. Risk factors for cancer of buccal and labial mucosa in Kerala, Southern India. J Epidemiol Community Health. 1990 Dec;44(4):286-92.

22. Macigo FG, Mwaniki DL, Guthua SW. The association between oral leukoplakia and use of tobacco, alcohol and Khat based on relative risks assessment in Kenya. Eur J Oral Sci. 1995 Oct; 103(5):268-73.

23. Thavarajah R, Rao A, Raman U, Rajasekaran ST, Joshua E, Hemalatha R, et.al. Oral lesions of 500 habitual psychoactive substance users in Chennai, India. Arch Oral Biol. 2006 Jun;51 (6):512-9.

24. Mathew AL, Daniel MP, Cherian SA. Prevalence of oral precancer and cancer in south kerala population. J. Oral Diag. 2017;02:e20170036. doi: 10.5935/2525-5711.20170036.

25. Mortazavi H, Baharvand M, Mehdipour M. Oral Potentially Malignant Disorders: An Overview of More than 20 Entities. J Dent Res Dent Clin Dent Prospects. 2014 Winter;8(1):6-14. doi: 10.5681/joddd.2014.002

26. Allen A, Williams J, Townsend N, Mikkelsen B, Roberts N, Foster C, et al. Socioeconomic status and non-communicable disease behavioural risk factors in low-income and lowermiddle-income countries: A systematic review. Lancet Glob Health. 2017 Mar;5(3):e277-e289. doi: 10.1016/S2214-109X(17)30058-X.

27. Vikneshan M, Ankola AV, Hebbal M, Sharma R, Suganya M. Patterns of tobacco usage and oral mucosal lesions of industrial workers: a cross sectional study. Austin J Public Health Epidemiol. 2016;3(1):1029.

28. Pahwa V,Nair S,Shetty RS, Kamath A. Prevalence of Oral Premalignant Lesions and Its Risk Factors among the Adult Population in Udupi Taluk of Coastal Karnataka, India. Asian Pac J Cancer Prev. 2018 Aug 24;19(8):2165-70 